\title{
Preoperative walking recommendation for non-cardiac surgery patients to reduce the length of hospital stay: a randomized control trial
}

\author{
Olga L. Cortés ${ }^{1 *}$, Mauricio Herrera-Galindo ${ }^{2}$, Claudia Becerra ${ }^{3}$, Mónica Rincón-Roncancio ${ }^{4}$, \\ Camilo Povea-Combariza ${ }^{5}$ and Maribel Esparza-Bohorquez ${ }^{6}$
}

\begin{abstract}
Background: Even though the importance of preparing patients for a surgical event is recognized, there are still gaps about the benefit of improving functional capacity by walking during the waiting time among patients scheduled for non-cardiac surgery. The aim of this study was to evaluate the impact of pre-surgical walking in-hospital length of stay, early ambulation, and the appearance of complications after surgery among patients scheduled for non-cardiac surgery.
\end{abstract}

Methods: A two-arm, single- blinded randomized controlled trial was developed from May 2016 to August 2017. Eligible outpatients scheduled for non-cardiac surgery, capable of walking, were randomized (2:1 ratio) to receive a prescription of walking $150 \mathrm{~min} /$ week during the whole pre-surgical waiting time $(n=249)$ or conventional care $(n=119)$. The primary outcome was the difference in hospital length of stay, and secondary results were time to first ambulation during hospitalization, description of ischemic events during hospitalization and after six months of hospital discharge, and the walking continuation. We performed an intention to treat analysis and compared length of stay between both groups by Kaplan-Meier estimator (log-rank test).

Results: There were no significant differences in the length of hospital stay between both groups (log-rank test $p=0.367$ ) and no differences in the first ambulation time during hospitalization (log-rank test $p=0.299$ ). Similar rates of postoperative complications were observed in both groups, but patients in the intervention group continued to practice walking six months after discharge $(p<0.001)$.

Conclusion: Our study is the first clinical trial evaluating the impact of walking before non-cardiac surgery in the length of stay, early ambulation, and complications after surgery. Prescription of walking for patients before noncardiac surgery had no significant effect in reducing the length of stay, and early ambulation. The results become a crucial element for further investigation.

Trial registration: PAMP-Phase2 was registered in ClinicalTrials.gov NCT03213496 on July 11, 2017.

Keywords: Non-cardiac surgery, Walking, Preoperative time, Length of hospital stay, Clinical trial

*Correspondence: ocortes@cardioinfantil.org

${ }^{1}$ Research Unit and Nursing Department, Fundación CardioinfantilInstituto de Cardiología, Cl. 163a \#13B-60, Bogotá D.C, Colombia

Full list of author information is available at the end of the article

\section{Background}

Globally, every year 200-millions of major non-cardiac surgeries are performed, mostly in adult populations $[1$, 2]. Between 2004 and 2012, there was a $38.2 \%$ increase original author(s) and the source, provide a link to the Creative Commons licence, and indicate if changes were made. The images or other third party material in this article are included in the article's Creative Commons licence, unless indicated otherwise in a credit line to the material. If material is not included in the article's Creative Commons licence and your intended use is not permitted by statutory regulation or exceeds the permitted use, you will need to obtain permission directly from the copyright holder. To view a copy of this licence, visit http://creativecommons.org/licenses/by/4.0/. The Creative Commons Public Domain Dedication waiver (http://creativeco mmons.org/publicdomain/zero/1.0/) applies to the data made available in this article, unless otherwise stated in a credit line to the data. 
in these surgeries (312 million/year), especially in developing countries [2]. In 2012, the global rate of general surgery was 4,469 operations per 100,000 people, which increased the total health expenditure by USD 400 USD per capita [1]. In the United States, in 2010, ten million non-cardiac surgeries were performed because of musculoskeletal disorders (84\%), neoplasia (61.4\%), lesions due to accidents (43.2\%), and digestive diseases (36.2\%), being the most prevalent problems [3]. Notably, cardiovascular complications after non-cardiac surgery happen within the first 30 days. These complications have affected more than 10 million people worldwide, with a mortality rate of around $1.5 \%$ [1].

One factor related to complications after these surgeries has been a sedentary lifestyle [3]. The prevalence of physical inactivity of adults scheduled for non-cardiac surgery was about 59\% in the Promoting ambulation project (PAMP) study phase I [4]. Inactivity may be a secondary consequence of the disease that has triggered the need for the surgery, or it may be related to other factors such as age and comorbidities that may determine the inability to perform daily living activities [5]. Preoperative variables such as low functional status present in sedentary patients have been associated with prolonged length of stay, and patients who stay longer in the hospital, have the worse clinical outcomes [8]. In this way, identifying that low functional status is a factor related to prolonged LOS in patients of scheduled non-cardiac surgery, promoting interventions such as walking, have the potential to reduce LOS also impacting hospital outcomes like costs, quality access, efficiency, and equity in hospital care [8].

However, despite knowing about the impact of exercise and physical activity on health outcomes $[6,7]$, there is a lack of information about the efficacy of a preoperative walking recommendation for non-cardiac surgery to reduce the length of stay (LOS) [6, 7]. The results about the impact of aerobic exercises, such as walking, are discordant concerning their impact and length of hospital stay when applied to patients before non-cardiac surgery. In the meta-analysis developed by Hughes (2019), in which the impact of aerobic exercise was evaluated in clinical trials, the investigators showed a reduction in the result in global morbidity and lung morbidity. Nevertheless, it did not show differences in the length of hospital stay or the evaluation of the post-surgical walk evaluated through the Six-minute walk test. These results of investigators interpret these results as the need to continue exploring the relationship between exercise patients before surgery and LOS. [9].

Accordingly, this study sought to evaluate the impact of the recommendation for walking a minimum of $150 \mathrm{~min} /$ week during waiting time before surgery compared with a control group in the length of hospital stay and early ambulation among adults scheduled for non-cardiac surgery. Likewise, this study aimed to describe the clinical complications during hospitalization and 30 days after surgery. We also reported the frequency of continuation of the practice of walking at six months after surgery.

\section{Methods}

This clinical trial study is reported according to CONSORT guidelines/methodology [9]. The study was registered retrospectively at Clinicaltrials.gov, NCT03213496 on July 11,2017 . We confirm that all methods were performed following the relevant guidelines and regulations regarding the protection and patient safety evaluated by the Ethics Committee in Research from FOSCAL clinic (Comité de Ética en Investigación CEI-FOSCAL) and the Ethics Committee in Clinical Research from Fundación Cardioinfantil Instituto de Cardiología (Comité de Ética en Investigación Clínica CEIC-IRB00007736). This study was considered of minimal risk by both Committees. All participants signed an informed consent form before the process of randomization.

\section{Study design}

The "Promoting ambulation project (PAMP) Phase II was a parallel-group, open-label, randomized controlled clinical trial including patients aged $\geq 30$ years, scheduled for non-cardiac surgery. Participants were assigned [ratio 2:1] to receive a structured prescription of $150 \mathrm{~min}$ weekly of walking before surgery along with all of their waiting time before surgery or usual care [Not receiving a recommendation of walking].

\section{Setting}

We recruited patients from two fourth-level university hospitals from two cities of Colombia that performed the study between May 10, 2016, to August 31, 2017; and the study protocol had approval by the Ethics Committee from both hospitals (Fundación Cardioinfantil Instituto de Cardiología, from Bogotá, and Clínica FOSCAL, Bucaramanga).

\section{Inclusion and exclusion criteria}

Patients were eligible if they were adults ( $\geq 30$ years), were scheduled for non-cardiac surgery under general or regional anesthesia (spinal or epidural), were able to mobilize upon admission, had to remain in the hospital for a minimum of $24 \mathrm{~h}$ after surgery, and were able to sign a consent form. We excluded patients with motor disabilities, state-of-consciousness alterations, uncontrolled chronic pain, and whose pre-surgical waiting time was known to be less than one week. 


\section{Sample size}

For this study's primary purpose, we considered a minimally significant difference to be one day of hospital stay. Based on our previous research, we estimated the mean hospital stay after non-cardiac surgical procedures at $2.2(\mathrm{SD}=1.1)$ and $3.3(\mathrm{SD}=0.8)$ days for the categories of early and late discharge, respectively (Cortés OL., 2018). Thus to detect a mean difference of one day of stay, conservatively considering a standard deviation of 2-3 days, with $90 \%$ statistical power (type I error probability $=0.05$ ), under a 2:1 randomization ration, the minimum sample size required was 368 patients ( 249 assigned to the intervention vs. 119 assigned to the control group).

\section{Randomization and blinding}

Randomization was performed using a computerized random number generator centralized at Fundación Cardioinfantil. Patients were allocated to an intervention group (walking prescription/accelerometer) or a conventional care group (without walking recommendation/ accelerometer) (Fig. 1). The patient allocation was kept by using sealed envelopes administered by a person not related to recruiting. Patients in the intervention group were assessed by one physiatrist doctor and also by a sports physician to prescribe the exercise and install the accelerometer. The surgeons or any physician provider of care of each patient, researchers, and analysts were blind regarding the assignation during pre, trans, and postoperatory time.

\section{Intervention and procedures}

Patients were recruited from the outpatients' list scheduled daily for non-cardiac surgery from each study site by a nurse coordinator of the study at each hospital. Eligible patients were approached at the end of the appointment with the surgeon in each of the centers and invited to participate in the study and, upon knowing the aims of the study and acceptance to participate, underwent randomization after signing a consent form in an individual interview.

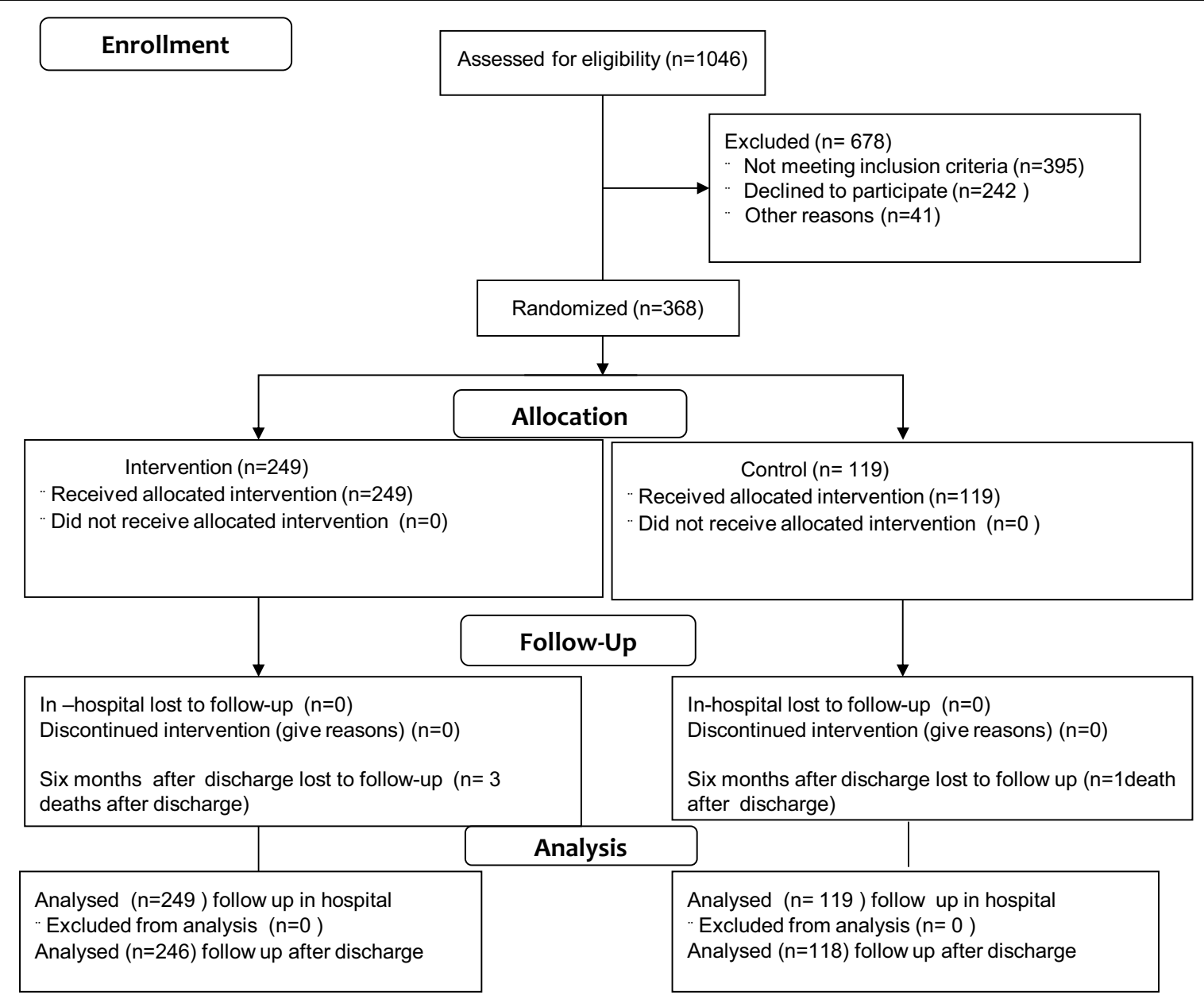

Fig. 1 Consort flow diagram 
This randomization included also a randomly assignation of twenty patients by each group to carry an accelerometer out to evaluate METs-min/week [metabolic equivalents], during the waiting time, as a way to validate walking adherence and determine differences between both groups.

Once patients signed the informed consents were evaluated based upon their demographic and medical history and also about baseline physical activity by a physician. This evaluation was carried out by two different doctors in different offices in order to avoid the risk of contamination of the intervention. All patients had to completed the International Physical Activity Questionnaire (IPAQshort) (Guidelines for the data processing and analysis of the "International Physical Activity Questionnaire, 2009) [10]. Using the IPAQ-short, they classified according to their physical level of activity as active $(1,500-3,000$ METs-min/week), with moderate exercise (600-1,499 METs-min/week), or sedentary (<600 METs-min/week).

Each patient allocated to the intervention group received individual walking instructions, face to face both verbally and in writing with a prescribed form, by a physician and a nurse. The education included walking at least $150 \mathrm{~min} /$ week, divided into sessions of $50 \mathrm{~min}$ daily at least three days/week, after warming up and stretch, to be performed throughout the whole pre-operatory waiting period. These patients also received instruction to complete a walking week-diary at home. They also received weekly-reinforcement calls to promote activity adherence before surgery. Patients in the control group did not receive any walking instruction.

We obtained and completed information from the patients' clinical variables (demographic, health antecedents, indication, type of surgery, evolution, complications, time to the first ambulation during hospitalization, and length of stay) retrospectively and collected the information from patients' diary provided on the surgery date. We contacted patients by phone calls after six months (week 12) after discharge. Patients from both groups were interviewed about post-surgical complications. Furthermore, patients in the intervention group were interviewed if they continued performing the doctor's prescription, and patients in the control group were asked about themselves in the present time they were performing any exercise, including walking.

\section{The accelerometer}

The equipment that was used to measure energy expenditure was the accelerometer actiheart ${ }^{\circledR}$ (CamNetech Ltd, UK). This device was implemented given its capacity to capture both the displacement in the three axes and simultaneously the heart frequency to obtain the energy expenditure (METs) accomplished with a minimum of
6 consecutive days of permanent use. For the analysis of the results, the accelerometer was recorded between days 1 to 6 . The data were captured and processed by the analyst of the study, blinded to the assignment of the intervention. The information for each accelerometer was integrated into a program with tools for data analysis [StataCorp. 2011.Stata Statistical Software:Release 12.College Station, TX:StataCorp LP] This program allowed data analysis to be sent to the project data analyst and then be integrated into the rest of the analysis.

\section{Study outcomes}

The primary outcome was the difference in length of hospital stay in days/hours. The secondary outcomes were time first to walk (ambulation) after surgery while in hospital and the frequency of ischemic events during hospitalization (acute myocardial infarction [AMI], cerebrovascular accident [CVA], deep venous thrombosis [DVT]), falls, and all causes of death. Events were assessed up to six months after discharge, including the continuity of walking for the intervened group and the initiative of walking for the conventional group.

\section{Statistical analysis}

The data analysis was performed using StataCorp.2011. Stata Statistical Software: Release 12. College Station, TX: StataCorp LP. Continuous variables were described using means (standard deviation) or medians (interquartile range) when non-normally distributed. Alternatively, we performed a logarithmic transformation to reduce said asymmetry. Discrete variables were described as counts (percentages). The Student's t-test was used to evaluate differences in means of continuous variables between study groups or the non-parametric KruskalWallis test to contrast variables whose distribution was not expected. We used the chi-squared test or the Fisher's exact test to assess differences in the distribution of discrete variables whenever the count expected in any cell of the contingency tables was $<5$ observations. Finally, a time-to-event analysis was performed, employing the Kaplan-Meier estimator and the log-rank test to determine differences in the hospital stay or the first walk between the intervention and the conventional group [11].

\section{Results}

Participants

Of the total number of patients included $(n=368)$, all completed the study (Fig. 1). There were no group differences on demographics, medical history at other experimental characteristics and control groups, indicating baseline comparability. There were minor differences related to socioeconomic status (Tables 1, 2). 
Table 1 Description of demographic characteristics of participants in the baseline

\begin{tabular}{|c|c|c|c|}
\hline Characteristic & $\begin{array}{l}\text { Intervention } \\
\mathrm{n}=\mathbf{2 4 9}(\%)\end{array}$ & $\begin{array}{l}\text { Control } \\
n=119(\%)\end{array}$ & $p$ value \\
\hline Age in years, mean (SD) & $59(11.8)$ & $59(13.0)$ & 0.970 \\
\hline Male & $124(49.8)$ & $51(42.9)$ & 0.212 \\
\hline \multicolumn{4}{|l|}{ Level of schooling } \\
\hline Elementary & 49 (19.6) & $30(25.2)$ & 0.349 \\
\hline High school & $62(24.9)$ & $34(28.6)$ & \\
\hline Technology/university & $138(55.5)$ & $55(46.2)$ & \\
\hline \multicolumn{4}{|l|}{ Occupation } \\
\hline Employed & $66(26.5)$ & $31(26.0)$ & 0.990 \\
\hline Independent worker & $74(29.7)$ & $37(31.1)$ & \\
\hline Retired/unemployed & $109(43.8)$ & $51(42.9)$ & \\
\hline \multicolumn{4}{|l|}{ Socioeconomic status } \\
\hline $1-2($ Low $)$ & $57(22.9)$ & $44(37.0)$ & 0.018 \\
\hline 3-4 (Intermediate) & $160(64.3)$ & $62(52.1)$ & \\
\hline 5-6 (High) & $32(12.8)$ & $13(10.9)$ & \\
\hline \multicolumn{4}{|l|}{ Marital status } \\
\hline Married & $155(62.3)$ & $63(52.9)$ & 0.445 \\
\hline Common-law & $37(14.8)$ & $21(17.7)$ & \\
\hline Single, widowed, or divorced & $57(22.9)$ & $35(29.4)$ & \\
\hline \multicolumn{4}{|l|}{ Origin } \\
\hline Urban & $236(94.8)$ & $110(92.4)$ & 0.375 \\
\hline Rural & $13(5.2)$ & $9(7.6)$ & \\
\hline
\end{tabular}

Values in each cell correspond to means (standard deviation), counts (proportions), or median [interquartile range].

SOAT Obligatory Traffic Accident Insurance

Related to physical activity assessment at baseline, the study population showed a Body Mass Index (BMI) over 26 (SD 3.4) and a higher prevalence of sedentarymoderate levels of physical activity (83.3-85.6\%) in both groups (Table 3). Regarding the type of surgical intervention, patients in the intervention and the control group required hospitalization for more than one night $(87.1 \%$ vs. $93.3 \%, p=0.077$ ), and a small proportion was discharged earlier than planned initially. The more prevalent length of stay was similar for both groups, and it was around two days for the intervention and the control group, respectively (63.0\% vs. $71.4 \%$ ) (Table 4$)$.

\section{Study outcomes \\ Description of events}

There were few cardiovascular events during hospitalization and after discharge. There was one death during hospitalization, one DVT, one fall in the intervention group, and no control group events. Six months after hospital discharge, there were two DVT (0.8\%) and three deaths in the intervention group (1.2\%), and one death in the control group $(0.8 \%)$ (Table 4$)$.
Table 2 Description of the health antecedents of participants in the baseline

\begin{tabular}{|c|c|c|c|}
\hline Medical antecedents & $\begin{array}{l}\text { Intervention } \\
(n=249)\end{array}$ & $\begin{array}{l}\text { Control } \\
(n=119)\end{array}$ & $p$ value \\
\hline \multicolumn{4}{|l|}{ Family health history, n (\%) } \\
\hline Arterial hypertension & $125(50.2)$ & $59(49.6)$ & 0.911 \\
\hline Diabetes & $90(36.1)$ & $31(26.1)$ & 0.054 \\
\hline Dyslipidemia & $67(26.9)$ & $27(22.7)$ & 0.385 \\
\hline Arrhythmia & $20(8.0)$ & $5(4.2)$ & 0.172 \\
\hline Peripheral vascular disease & $42(16.9)$ & $15(12.6)$ & 0.290 \\
\hline Transient ischemic attack & $9(3.6)$ & $5(4.2)$ & 0.776 \\
\hline Cerebral vascular disease & $29(11.7)$ & $9(7.6)$ & 0.229 \\
\hline Myocardial infarction & $68(27.3)$ & $24(20.2)$ & 0.139 \\
\hline COPD & $15(6.0)$ & $10(8.4)$ & 0.396 \\
\hline Active cancer & $98(39.4)$ & $53(44.5)$ & 0.345 \\
\hline \multicolumn{4}{|l|}{ Cardiovascular risk, n (\%) } \\
\hline Current smoking & $7(2.8)$ & $6(5.0)$ & 0.365 \\
\hline Arterial hypertension & $93(37.4)$ & $44(37.0)$ & 0.945 \\
\hline Dyslipidemia & $46(18.5)$ & $23(19.3)$ & 0.844 \\
\hline Diabetes mellitus & $22(8.8)$ & $8(6.7)$ & 0.488 \\
\hline \multicolumn{4}{|l|}{ Cardiovascular disease, n (\%) } \\
\hline Arrhythmia & $13(5.2)$ & $6(5.0)$ & 0.942 \\
\hline Peripheral vascular disease & $29(11.7)$ & $12(10.1)$ & 0.656 \\
\hline Transient ischemic attack & $4(1.6)$ & $4(3.4)$ & 0.279 \\
\hline Cerebral vascular disease & $0(0.0)$ & $1(0.8)$ & 0.323 \\
\hline Myocardial infarction & $9(3.6)$ & $3(2.5)$ & 0.758 \\
\hline \multicolumn{4}{|l|}{ Other comorbidities, n (\%) } \\
\hline COPD & $4(1.6)$ & $2(1.7)$ & 1.000 \\
\hline Cancer & $53(21.3)$ & $38(31.9)$ & 0.027 \\
\hline Total prior surgeries & $2.0[3.0]$ & $2.0[2.0]$ & 0.066 \\
\hline \multicolumn{4}{|l|}{$\begin{array}{l}\text { Medications taken chronically } \\
\text { before surgery, } \mathrm{n}(\%)\end{array}$} \\
\hline Antihypertensive & $93(37.4)$ & $46(38.7)$ & 0.809 \\
\hline Beta-blocker & $16(6.4)$ & $12(10.1)$ & 0.216 \\
\hline Statins & $50(20.1)$ & $17(14.3)$ & 0.179 \\
\hline Diuretics & $10(4.0)$ & $11(9.2)$ & 0.043 \\
\hline Gastric mucosal protectors & $20(8.0)$ & $11(9.2)$ & 0.695 \\
\hline $\begin{array}{l}\text { Prophylactic antithrombotic } \\
\text { agent }\end{array}$ & $27(10.8)$ & $17(14.3)$ & 0.341 \\
\hline
\end{tabular}

Values in each cell correspond to means (standard deviation), counts (proportions), or median [interquartile range]

COPD Chronic obstructive pulmonary disease, NSAI non-steroidal antiinflammatory

\section{Before surgery walk validation}

The median surgical waiting time was about 15 days (IQR 3-233) for the intervention group and 17 days (IQR 3-378) for the control group, with no significant differences (Table 4). The energy expenditure during physical activity (METs/hr.) median differences between both groups using accelerometers showed significant differences. Patients in the intervened 
Table 3 Findings of physical exam upon admission and level of physical activity in the baseline

\begin{tabular}{|c|c|c|c|}
\hline Characteristic & $\begin{array}{l}\text { Intervention } \\
(n=249)\end{array}$ & $\begin{array}{l}\text { Control } \\
(n=119)\end{array}$ & $p$ value \\
\hline \multicolumn{4}{|l|}{ Assessment upon admission (SD) } \\
\hline Heart rate (bpm) & $74.2(10.5)$ & $73.1(10.5)$ & 0.200 \\
\hline Systolic blood pressure (mmHg) & $120.6(16.4)$ & $118.4(14.9)$ & 0.246 \\
\hline Diastolic blood pressure (mmHg) & $71.9(9.2)$ & $71.1(9.7)$ & 0.606 \\
\hline Breathing frequency (rpm) & $17.4(2.3)$ & $17.2(2.1)$ & 0.250 \\
\hline Body mass index $\left(\mathrm{kg} / \mathrm{m}^{2}\right)$ & $26.7(4.0)$ & $26.1(3.4)$ & 0.215 \\
\hline Waist-hip index & $0.94(0.10)$ & $0.93(0.13)$ & 0.574 \\
\hline \multicolumn{4}{|c|}{ Physical activity-patient perception, n (\%) } \\
\hline Frequent & $65(26.1)$ & $35(29.4)$ & 0.753 \\
\hline Occasional & $105(42.2)$ & $46(38.7)$ & \\
\hline Sedentary & $79(31.7)$ & $38(31.9)$ & \\
\hline METS on admission (IPAQ) & $721.5[858.5]$ & $796.0[834.0]$ & 0.157 \\
\hline \multicolumn{4}{|l|}{ Level of physical activity (IPAQ), n (\%) } \\
\hline Sedentary & $109(43.8)$ & $46(38.7)$ & 0.626 \\
\hline Moderate & $104(41.8)$ & $53(44.5)$ & \\
\hline Active & $36(14.5)$ & $20(16.8)$ & \\
\hline
\end{tabular}

Values in each cell correspond to means (standard deviation), counts (proportions), or median [interquartile range].

IPAQ: International Physical Activity Questionnaire

group walked 403 [IQR 268; 630] $\mathrm{min} /$ week, whereas patients in the control group walked $237 \mathrm{~min} /$ week [IQR 200; 321] ( $p=0.003)$. These differences remained for individuals with low and moderate walking intensities (1.5-3.0 MET, $p=0.004 ; 3.1-6.0 \mathrm{MET} p=0.025)$, respectively (Table 5 , Fig. 2 ).

\section{During hospitalization and after hospital discharge}

Although we observed that a smaller fraction of patients in the intervened group remained hospitalized compared with the control group (63.1\% vs. $71.4 \%, p=0.188)$ (Table 4), there were no statistically significant differences in length of hospital stay (log-rank test $p=0.367$ ). Likewise, there were no significant differences in the beginning ambulation during the post-operatory period between both groups (log-rank test $p=0.299$ ) (Figs. 3, 4). After surgery, the first ambulation was more often observed between the bed and the bathroom in the in the intervention group (65.9\%) than in the control group (73.1\%).

After six months of hospital discharge we identified significant differences (Chi square) in walking behavior. Patients in the intervention self-reported they continue walking according to the doctor's prescription before surgery. They were more likely to continue walking [76.7\%, $\mathrm{n}=191$ of $243,95 \%$ CI 164 to 220.09 ] than patients in the conventional group [38.0\%, $\mathrm{n}=44$ of $118,95 \%$ CI 31.9 to 59.06)] $(p<0.001)$.

\section{Discussion}

In this trial, the prescription of walking $150 \mathrm{~min}$ each week during the waiting time, compared with conventional care for adults going to non-cardiac surgery, did not reduce the length of stay or the time to the first ambulation of patients during hospitalization. Similar rates of postoperative complications were observed in both groups. However, significantly patients in the intervention group self-reported continue to practice walking six months after discharge.

A meta-analysis of data from trials involving 347 patients scheduled for cardiac surgery, aerobic exercise before surgery showed a significant reduction in length of stay of 3.2 days (mean -3.2 , 95\% IC $-5.73,-0.69$ ] [6]. Being consistent with our results, two meta-analyses of aerobic exercise before general surgery have shown no impact on hospital stay length. Moran et al. [12] developed the systematic review, including 435 patients (from randomized controlled trials) undergoing intra-abdominal surgery, evaluated the effect of inspiratory muscles training, aerobic exercise, and resistance training before surgery in outcomes post-surgery [12]. It showed a reduction of complications (odds ratio $0.59,95 \% \mathrm{CI}$ $0.38,0.91, p=0.03)$, but it could not show differences in length of stay (mean $-1.62,95 \% \mathrm{CI}-75,4.3$ days). A recent meta-analysis of data from trials involving 927 patients scheduled for gastrointestinal surgery related to cancer, the prehabilitation programs, including aerobic exercise, showed no differences between groups related 
Table 4 Description of characteristics of surgery and procedures performed during hospitalization

\begin{tabular}{|c|c|c|c|}
\hline Characteristic & $\begin{array}{l}\text { Intervention } \\
(n=249)\end{array}$ & $\begin{array}{l}\text { Control } \\
(n=119)\end{array}$ & $p$ value \\
\hline Surgical waiting time (mean days, min and max) & $15[3-233]$ & $17[3-378]$ & 0.668 \\
\hline Surgical time hour: min (RI) & $1: 42(1: 29)$ & $1: 54(1: 30)$ & 0.209 \\
\hline \multicolumn{4}{|l|}{ Length of stay days, n (\%) } \\
\hline$<1$ & $30(12.1)$ & $8(6.7)$ & \multirow[t]{3}{*}{0.188} \\
\hline $1-2$ & $62(24.9)$ & $26(21.9)$ & \\
\hline$>2$ & $157(63.0)$ & $85(71.4)$ & \\
\hline \multicolumn{4}{|l|}{ Type of surgery, n (\%) } \\
\hline Surgery modified to ambulatory & $32(12.9)$ & $8(6.7)$ & \multirow[t]{2}{*}{0.077} \\
\hline Required hospitalization for more than $24 \mathrm{~h}$ & $217(87.1)$ & $111(93.3)$ & \\
\hline \multicolumn{4}{|l|}{ Scheduled surgery, n (\%) } \\
\hline General surgery & $60(24.1)$ & $25(21.0)$ & \multirow[t]{5}{*}{0.296} \\
\hline Urology & $101(40.6)$ & $56(47.1)$ & \\
\hline Gynecology & $41(16.5)$ & $22(18.5)$ & \\
\hline Orthopedic & $30(12.0)$ & $6(5.0)$ & \\
\hline Other specialties & $17(6.4)$ & $10(8.4)$ & \\
\hline \multicolumn{3}{|l|}{ Type of anesthesia, n (\%) } & \multirow[t]{4}{*}{0.603} \\
\hline General & $195(78.3)$ & $87(73.1)$ & \\
\hline Regional & $50(20.1)$ & $30(25.2)$ & \\
\hline Other & $2(1.7)$ & $4(1.6)$ & \\
\hline \multicolumn{3}{|l|}{ Type of wound, n (\%) } & \multirow[t]{4}{*}{0.083} \\
\hline Clean & $83(33.3)$ & $30(25.2)$ & \\
\hline Clean contaminated & $166(66.7)$ & $88(73.9)$ & \\
\hline Contaminated & $1(0.8)$ & $0(0)$ & \\
\hline \multicolumn{3}{|l|}{ Type of incision, $n(\%)$} & \multirow[t]{3}{*}{0.575} \\
\hline Open & $152(61.0)$ & $69(58.0)$ & \\
\hline Laparoscopy & $97(39.0)$ & $50(42.0)$ & \\
\hline \multicolumn{4}{|l|}{ Complications during hospitalization, n (\%) } \\
\hline Death & $1(0.4)$ & 0 & \\
\hline DVT (Deep Venous Thrombosis) & $1(0.4)$ & 0 & \\
\hline Fall & $1(0.4)$ & 0 & \\
\hline \multicolumn{4}{|l|}{ Complications six months after the surgery, $\mathrm{n}(\%)$} \\
\hline Death & $3(1.2)$ & $1(0.8)$ & 0.749 \\
\hline DVT (Deep Venous Thrombosis) & $2(0.8)$ & 0 & 0.328 \\
\hline
\end{tabular}

Values in each cell correspond to means (standard deviation), counts (proportions), or median [interquartile range]

to complications after surgery, mortality, and length stay [13].

In the non-surgical setting, aerobic exercise has proved to produce positive changes in cardiorespiratory function and physical performance in general populations and populations at risk, such as the elderly $[14,15]$. However, in our study, walking before non-cardiac surgery did not show differences in length of stay, early ambulation postsurgery, or any impact associated with complications. We offer some potential explanations for these findings. First, walking is frequently prescribed as part of patients' physical preparation before general surgery, although there is a lack of evidence to demonstrate its aerobic benefits [7,
24]. Exercise modifies body composition, cardiovascular fitness, flexibility, muscular endurance, and strength and improves physical activity by $85 \%$, as it has been demonstrated in solid research-based in healthy individuals and patients going to cardiovascular surgery. However, there is a low quality of evidence [7] about the impact that may provide unsupervised walking before surgery in patients' outcomes during hospitalization and after discharge, mainly when this evidence is based on indirectness [respiratory exercises, cycling, but no unsupervised walking] and inconsistency of the results of the studies [24].

Second, walking intervention, which can be performed by patients at home or in an unsupervised way, represents 
Table 5 Description of physical activity before surgery, during hospitalization, and after discharge

\begin{tabular}{|c|c|c|c|}
\hline Characteristic & $\begin{array}{l}\text { Intervention } \\
(n=249)\end{array}$ & $\begin{array}{l}\text { Control } \\
(n=119)\end{array}$ & $p$ value \\
\hline \multicolumn{4}{|l|}{ Activity validation before surgery } \\
\hline Accelerometer users & $20(8.4)$ & $20(16.8)$ & - \\
\hline \multicolumn{4}{|l|}{ Physical activity (min/week) } \\
\hline Low (1.5-3.0 MET) & $358[230-507]$ & $196[166-255]$ & 0.004 \\
\hline Moderate (3.1-6.0 MET) & $45[38-86]$ & $26[4-47]$ & 0.025 \\
\hline Vigorous (6.1-9.0 MET) & $0[0-1]$ & $0[0-1]$ & 0.952 \\
\hline Total & $403[268,630]$ & $237[200,321]$ & 0.003 \\
\hline \multicolumn{4}{|l|}{ Time to first walk after surgery in hospital (hours), n (\%) } \\
\hline Walk before to $24 \mathrm{~h}$ & $153(61.4)$ & $68(57.1)$ & 0.710 \\
\hline Walk between 24 and $72 \mathrm{~h}$ & $88(35.3)$ & $47(39.5)$ & \\
\hline Walk time over $72 \mathrm{~h}$ & $8(3.2)$ & $4(3.4)$ & \\
\hline \multicolumn{4}{|l|}{ Place of first ambulation, $\mathrm{n}(\%)$} \\
\hline Around the bed & $13(5.2)$ & $7(5.9)$ & 0.218 \\
\hline From the bed to the bathroom & $164(65.9)$ & $87(73.1)$ & \\
\hline From the bed to the hallway & $35(14.1)$ & $9(7.6)$ & \\
\hline Through the hallway & $7(2.8)$ & $6(5.0)$ & \\
\hline Other & $30(12.0)$ & $10(8.4)$ & \\
\hline \multicolumn{4}{|l|}{ Following walking behavior after six months from the surgery } \\
\hline Were you walking after surgery at least 150 min at the week? Yes & $191(76.7)$ & $44(36.9)$ & $<0.001$ \\
\hline
\end{tabular}

METS is defined as the amount of oxygen consumed while sitting at rest and is equal to $3.5 \mathrm{ml} \mathrm{O}_{2}$ per kg body weight $\times$ min

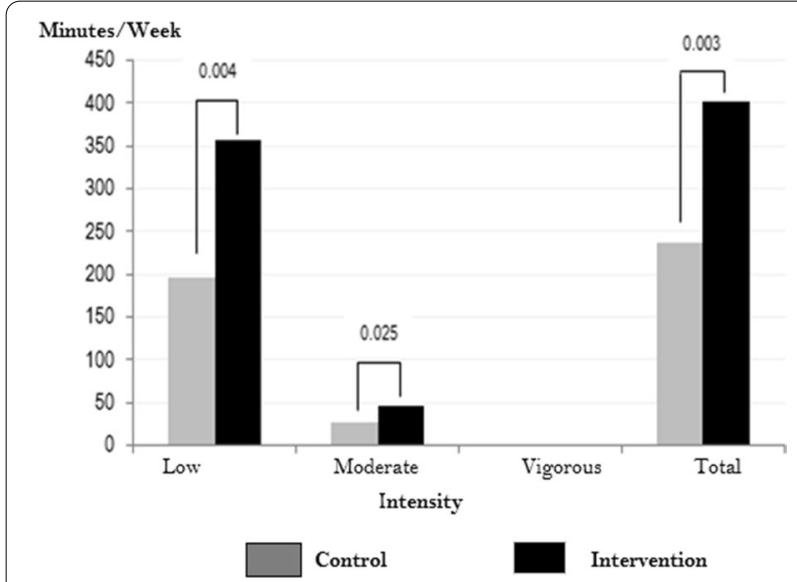

Fig. 2 Time median (minutes/week) of physical activity measured using accelerometers, by intensity and group. Estimations are based on 20 patients for each group. Intensity: low (1.5-3.0 MET), moderate (3.1-6.0 MET), and vigorous (6.1-9.0 MET). $p$ values estimated were obtained via the Kruskal-Wallis test

a low- moderate-intensity aerobic exercise that may not improve its components within a variable short time as it is the surgical waiting time (median of 15 days in our study). Third, given that walking provides low-moderate intensity as an aerobic exercise, in some other studies, this intervention was being provided to the participants

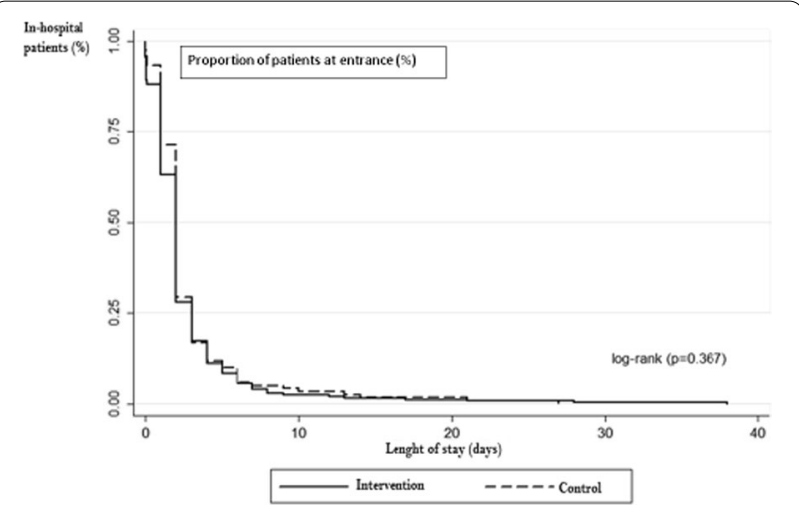

Fig. 3 Time at discharge (of hospital stay) in the intervention and control group. No differences were noted in the time of stay between the groups. (log-rank test $p=0.367$ )

involved in the control group; since no differences were observed between the groups, there is a possibility that walking may be effective $[12,13]$. Fourth, the baseline level of physical activity identified in both groups in our study was predominantly low to moderate; these patients may have required a higher level of intensity of exercise to produce a change in LOS $[16,17]$.

Other factors that could have affected the LOS in our study are the surgical time of fewer than $2 \mathrm{~h}$, the age of 


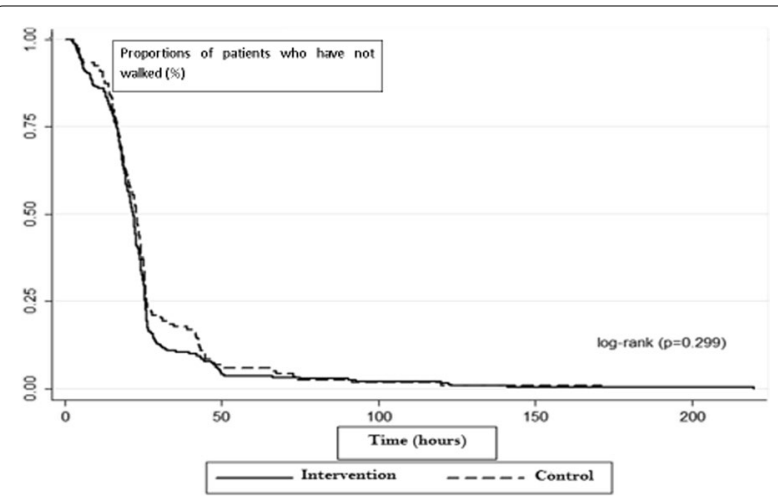

Fig. 4 Time to the first ambulation during hospitalization of intervention and control group. No differences were noted in the first walk during the post-operatory between both groups (log-rank test $p=0.299)$

patients below 59 years old, mostly women, and the majority living with their families. It has been described that early discharge to home is perceived for patients as early recovery and a restoration of their social network, an early return to work, and early ambulation may be more accelerated in some demographic groups like those that need to resume their functions promptly $[17,18]$.

The significant adherence to the intervention group's physical activity six months after hospital discharge is consistent with other results identified in non-surgery studies aimed to motivate behavior changes and improve health outcomes $[18,19]$. We consider a potential explanation for this finding. Previous studies have shown that patients' significant adherence to walking was associated with the type of health provider that gave the prescription or the class of motivational intervention provided by health workers $[20,21]$. In our study, the physician provided the prescription, an expert in rehabilitation, in a written form to establish a medical order that had to be carried out. It may happen that weekly reinforcements provided to the intervention group before surgery by their physician had motivated the patients to continue walking after discharge.

\section{Implementation for practice and research}

The standardized indication of walking $150 \mathrm{~min} /$ week is based on physical activity recommendations determined by the exercise guidelines aimed at adults and the elderly, which indicates some benefits in the pre-operatory phase, like reducing BMI [22]. However, these guidelines still do not contain precise recommendations about the population that would benefit more from walking and the frequency/ intensity of the exercises that could improve clinical outcomes when applied before surgery [7, 22, 23]. A significant impact of walking before surgery can be observed if implemented during a time greater than 4 or 6 weeks, providing reinforcements of walking during the post-operatory period, as shown in some studies [12]. Hence, we do not know the best frequency and intensity of walking that would improve functional capacity before surgery, impacting LOS and complications after surgery.

Controlled clinical trials are the best epidemiological design to assess new interventions and medications' effectiveness and safety. Despite being studies with random assignment, clinical trials have limitations that can diminish the clinical validity of these and their applicability in certain groups of populations. Limitations in our study can be related to; first, recall bias of the patients in the intervention group to remember the time or the intervention despite the reinforcement calls provided weekly to them. Second, although we identified significant differences in compliance of walking before surgery by users of accelerometers in favor of the intervention group compared to the control group, the restricted number of accelerometers available limited a complete validation of the intervention's adherence. Third, the use of a diary to self-report the walking activity in consequence. The last limitation is related to our healthcare system's structure, which often delays information regarding the final authorization for the surgery dates. This factor may have affected the length of waiting times producing significant variability in pre-surgical times, affecting the intervention's efficacy.

\section{Conclusions}

Our study is the first clinical trial evaluating the impact of walking before non-cardiac surgery in the length of stay, early ambulation, and complications after surgery. In conclusion, the prescription of a pre-surgical standardized 150-min walk per /week before non-cardiac surgery had no significant effect on length of stay or early ambulation and complications after surgery. The results do not support the use of simple walking prescription before non-cardiac surgery for reducing the length of hospital stay in adults.

The results become a crucial element for further investigation.

\section{Abbreviations \\ LOS: Length of hospital stay; PAMP: Promoting ambulation project; MET: Meta- bolic equivalent (MET), amount of oxygen consumed while sitting at rest and is equal to $3.5 \mathrm{ml} \mathrm{O} 2$ per kg body weight $\times$ min.; IPAQ: International Physical Activity Questionnaire; AMl: Acute myocardial infarction; CVA: Cerebrovascular accident; DVT: Deep venous thrombosis; BMI: Body Mass Index; CARDIECOL PROGRAM: Knowledge and action to reduce cardiovascular disease in Colombia.}

\section{Acknowledgements}

The authors would like to thank all the patients who were willing to participate in the study. 


\section{Authors' contributions}

This study protocol was carried out in collaboration with all authors. OLC developed the study design. OLC, MEB, and CB were involved in planning, coordinating, and managing data acquisition at the study site. MRR performed the pre-surgery patient assessment and prescription. CPC evaluated the group of patients assigned to receive an accelerometer and performed the following. MHG was blinded to the data, and he analyzed the raw data and performed the statistical analysis. OLC wrote the first draft of the manuscript, MHG, MRR, CPC, MEB revised the manuscript. All authors have read and approved the final version of the manuscript.

\section{Funding}

This study was funded by the Grant from the Department of Science, Technology, and Colombia innovation. COLCIENCIAS, No. 617399847755, 2014-2017, as one of the CARDIECOL Program projects [998-2014]. The funder had no role in the study's design, the collection, analysis, and interpretations of data, or writing the manuscript.

\section{Availability of data and materials}

The datasets used and analyzed during the current study are available from the corresponding author on Mendeley repository (https://doi.org/10.17632/ ft7r4wrnt3.1).

\section{Declarations}

\section{Ethics approval and consent to participate}

The study was approved by the Ethical Committee of the Fundación Cardioinfantil Instituto de Cardiología (CEIC IRB0000 No458, October 2014) and by the Ethical committee of the FOSCAL (CEI FOSCAL No60, September 2016). Written informed consent was obtained from all participants after a verbal explanation, and written information was provided.

\section{Consent for publication}

Not applicable.

\section{Competing interests}

The authors OLC, MHG, MR, CPB, ME, and CP declare that they have no competing interests.

\section{Author details \\ ${ }^{1}$ Research Unit and Nursing Department, Fundación Cardioinfantil-Instituto de Cardiología, Cl. 163a \#13B-60, Bogotá D.C, Colombia. ${ }^{2}$ Faculty of Health Sciences, Universidad Autónoma de Bucaramanga, Avenida 42 No 48-11 PBX, Bucaramanga, Colombia. ${ }^{3}$ Nursing Department, Fundación Cardioinfantil-Insti- tuto de Cardiología, Cl. 163a \#13B-60, Bogotá D.C, Colombia. ${ }^{4}$ Cardiovascular Rehabilitation Department, Fundación Cardioinfantil-Instituto de Cardiología, Cl. 163a \#13B-60, Bogotá D.C, Colombia. ${ }^{5}$ Faculty of Medicine, Universidad Nacional de Colombia, Cra 45, Bogotá D.C, Colombia. ${ }^{6}$ Nursing Department, Fundación Oftalmológica de Santander-Clínica Carlos Ardila Lulle, FOSCAL, Calle 155A No23-60, Floridablanca, Colombia.}

Received: 28 December 2020 Accepted: 7 July 2021

Published online: 28 July 2021

\section{References}

1. Weiser TG, Haynes AB, Molina G, Lipsitz SR, Esquivel MM, Uribe-LeitzT, et al. Size and distribution of the global volume of surgery in 2012. Bull World Health Organ. 2016;94(3):201-209F. https://doi.org/10.2471/BLT.15. 159293.

2. Lee S-H, Park MS, Song YB, Park J, Kim J, Lee SM, et al. Perioperative myocardial injury in revascularized coronary patients who undergo noncardiac surgery. PLoS ONE. 2019;14(6): e0219043. https://doi.org/10.1371/ journal.pone.0219043.

3. Hoogeboom TJ, Dronkers JJ, Hulzebos EH, van Meeteren NL. Merits of exercise therapy before and after major surgery. Curr Opin Anaesthesiol. 2014;27:161-6. https://doi.org/10.1097/AC0.0000000000000062.

4. Cortés OL, Moreno K, Alvarado P, Povea C, Lloyd M. Inactivity and its associated factors in adults scheduled for non-cardiac surgery: the PAMP phase I study. Rehabilitation Nur. 2018;43:81-7. https://doi.org/10.1002/ rnj.309.

5. Santa Mina D, Scheede-Bergdahl C, Gillis C, Carli F. Optimization of surgical outcomes with prehabilitation. Appl Physiol Nutr Metab. 2015;40(9):966-9. https://doi.org/10.1139/apnm-2015-0084.

6. Hulzebos EH, Smit Y, Helders PP, van Meeteren NL. Preoperative physical therapy for elective cardiac surgery patients. Cochrane Database Syst Rev. 2012;11:CD010118. https://doi.org/10.1002/14651858.CD010118.pub2.

7. Tew GA, Ayyash R, Durrand J, Danjoux GR. Clinical guideline and recommendations on preoperative exercise training in patients awaiting major non-cardiac surgery. Anaesthesia. 2018;73(6):750-68. https://doi.org/10. 1111/anae.14177.

8. Collins TC, Daley J, Henderson WH, Khuri SF. Risk factors for prolonged length of stay after major elective surgery. Ann Surg. 1999;230(2):251-9. https://doi.org/10.1097/00000658-199908000-00016.

9. Hughes MJ, Hackney RJ, Lamb PJ, et al. Prehabilitation before major abdominal surgery: a systematic review and meta-analysis. World J Surg. 2019;43:1661-8. https://doi.org/10.1007/s00268-019-04950-y.

10. Hagströmer M, Oja P, Sjöström M. The International Physical Activity Questionnaire (IPAQ): a study of concurrent and construct validity. Public Health Nutr. 2006;9(6):755-62. https://doi.org/10.1079/phn2005898.

11. Goel MK, Khanna P, Kishore J. Understanding survival analysis: KaplanMeier estimate. Int J Ayurveda Res. 2010;1 (4):274-8. https://doi.org/10. 4103/0974-7788.76794.

12. Moran J, Guinan E, McCormick P, Larkin J, Mockler D, Hussey J, Moriarty $J$, Wilson F. The ability of prehabilitation to influence postoperative outcome after intra-abdominal operation: a systematic review and metaanalysis. Surgery. 2016;160(5):1189-201. https://doi.org/10.1016/j.surg. 2016.05.014.

13. Lau CSM, Chamberlain RS. Prehabilitation programs improve exercise capacity before and after surgery in gastrointestinal cancer surgery patients: a meta-analysis. J Gastrointest Surg. 2020;24(12):2829-37. https://doi.org/10.1007/s11605-019-04436-1.

14. Tsuji I, Takahashi K, Nishino Y, Ohkubo T, Kuriyama S, Watanabe Y, Anzai Y, Tsubono Y, Hisamichi S. Impact of walking upon medical care expenditure in Japan: The Ohsaki Cohort Study. Int J Epidemiol. 2003;32(5):80914. https://doi.org/10.1093/ije/dyg189.

15. Saint-Maurice PF, Troiano RP, Bassett DR Jr, Graubard BI, Carlson SA, Shiroma EJ, Fulton JE, Matthews CE. Association of daily step count and step intensity with mortality among US adults. JAMA. 2020;323(12):1151-60. https://doi.org/10.1001/jama.2020.1382.

16. Kim RY, Murphy TE, Doyle M, Pulaski C, Singh M, Tsang S, Wicker D, Pisani MA, Connors GR, Ferrante LE. Factors associated with discharge home among medical ICU patients in an early mobilization program. Crit Care Explor. 2019;1(11): e0060. https://doi.org/10.1097/CCE.0000000000 000060.

17. Regenbogen SE, Cain-Nielsen AH, Norton EC, Chen LM, Birkmeyer JD, Skinner JS. Costs and consequences of early hospital discharge after major inpatient surgery in older adults. JAMA Surg. 2017;152(5): e170123. https://doi.org/10.1001/jamasurg.2017.0123.

18. Tudor-Locke C, Bell RC, Myers AM, Harris SB, Ecclestone NA, Lauzon N, Rodger NW. Controlled outcome evaluation of the First Step Program: a daily physical activity intervention for individuals with type ii diabetes. Int J Obes. 2004;28(1):113-9. https://doi.org/10.1038/sj.ijo.0802485.

19. Plotnikoff RC, Pickering MA, Glenn N, Doze SL, Reinbold-Matthews ML, McLeod LJ, Lau DC, Fick GH, Johnson ST, Flaman L. The effects of a supplemental, theory-based physical activity counseling intervention for adults with type 2 diabetes. J Phys Act Health. 2011;8(7):944-54. https:// doi.org/10.1123/jpah.8.7.944.

20. Bittner $\bigvee$, Sanderson B, Breland J, Green D. Referral patterns to a University-based cardiac rehabilitation program. Am J Cardiol. 1999;83(2):252-5, A5. https://doi.org/10.1016/s0002-9149(98)00830-3.

21. Ghisi GL, Polyzotis P, Oh P, Pakosh M, Grace SL. Physician factors affecting cardiac rehabilitation referral and patient enrollment: a systematic review. Clin Cardiol. 2013;36(6):323-35. https://doi.org/10.1002/clc.22126.

22. American College of Sports Medicine, Chodzko-Zajko WJ, Proctor DN, Fiatarone Singh MA, Minson CT, Nigg CR, Salem GJ, Skinner JS. American College of Sports Medicine position stand. Exercise and physical activity for older adults. Med Sci Sports Exerc. 2009;41(7):1510-30. https://doi. org/10.1249/MSS.0b013e3181a0c95c. 
23. Chen BP, Awasthi R, Sweet SN, Minnella EM, Bergdahl A, Santa Mina D, Carli F, Scheede-Bergdahl C. Four-week prehabilitation program is sufficient to modify exercise behaviors and improve preoperative functional walking capacity in patients with colorectal cancer. Support Care Cancer. 2017;25(1):33-40. https://doi.org/10.1007/s00520-016-3379-8.

24. Piccioni F, Droghetti A, Bertani A, et al. Recommendations from the Italian intersociety consensus on Perioperative Anesthesia Care in Thoracic surgery (PACTS) part 1: preadmission and preoperative care. Perioper Med. 2020;9:37. https://doi.org/10.1186/s13741-020-00168-y.

\section{Publisher's Note}

Springer Nature remains neutral with regard to jurisdictional claims in published maps and institutional affiliations.
Ready to submit your research? Choose BMC and benefit from:

- fast, convenient online submission

- thorough peer review by experienced researchers in your field

- rapid publication on acceptance

- support for research data, including large and complex data types

- gold Open Access which fosters wider collaboration and increased citations

- maximum visibility for your research: over 100M website views per year

At BMC, research is always in progress.

Learn more biomedcentral.com/submissions 